XXXIII. On the nictitans group of the Genus Hydroecia, Gn. By the Rev. C. R. N. Burrows, F.E.S.

[Read December 6th, 1911.]

\title{
Plates LI-LViII.
}

IT will be remembered that Mr. Tutt delivered a short address upon the "Separation of British Species of Hydroecia" before this Society on March 16th, 1910. The address was illustrated by drawings of the four different forms of genitalia in both sexes, which Mr. Pierce and I had detected in the insects which had been included by most Lepidopterists under the name of Hydroecia nictitans. It was with great pleasure that I listened to Mr. Tutt, as I felt that it was only right that he, who had twenty years before suggested the specific distinctness of $H$. paludis and $H$. lucens, should make the announcement that this distinctness had been clearly proved. Unfortunately, it was not at that time possible to publish the illustrations which are so necessary to elucidate the points of difference between insects which resemble one another so closely, and it was understood that later on Mr. Tutt would put the matter more definitely before the Society. He had taken up the matter whole-heartedly, was engaged in examining the points himself, and supervising the execution of the necessary illustrations, when his last illness overtook him, and the matter had to be shelved.

It is under these circumstances that I have been urged to carry out what Mr. Tutt planned, and I ask indulgence if I seem to fall short of the lucidity which that lamented entomologist could command.

In the "Entomologist" for 1888, p. 307, I find what I believe to be the first public intimation of Mr. Tutt's dissatisfaction with the specific identity of the various forms then accepted as $H$. nictitans. He there treats the form which he names paludis as a local race, or variety, of nictitans. Lucens, which had been introduced as a separate species by Freyer and accepted by HerrichSchaeffer as such, he recognises as "really nictitans, and not distinct."

TRANS. ENT. SOC. LOND. 1911.-PART IV. (JAN.) 
When he published his work on "The Variation of the British Noctuidae," British entomologists were still content to recognise as one single species all the various forms which they called $H$. nictitans. $\mathrm{He}$, in the first volume (1891), tentatively suggested that under this name we had really two, if not three, different species : and actually separated the forms paludis, Tutt, and lucens, Frr., as sub-species, from nictitans, L.

In 1895 ("Entom. Record," vol. vii, p. 78), he published an article, nominally by T. Acton, but actually by himself, under the title, "Varieties of Noctuidae at Warrington," in which he deals again with these puzzling forms, and states that further information supported what he had written and to a large extent had emphasised the distinctness of nictitans, paludis, and lucens.

Dr. J. B. Smith in 1899-1900 published his paper dealing with the North American Hydroecias, ${ }^{*}$ and figured the "clasps" ("valves") of thirty-six species, thirty-five American, and one which he calls nictitans. The figure is not of nictitans, but probably lucens, or possibly paludis. He writes of nictitans, but does not give the faintest indication that he has heard that Tutt had already stated his conviction, that European nictitans could be differentiated into three probable species. Nor is an American, who might be excused, the only writer who has appeared ignorant of what has been done and suggested by Tutt in this investigation. Dr. Smith says of the American species, "These species, which have in the past been considered as identical with European nictitans, agree in trigonate, pointed primaries, which are in general a shade of brick-red, and in which the onter margin is even. In general maculation all are alike, having all the usual lines and spots, and none of them strongly contrasting. The lines are a deeper shade of red-brown, and the transverse posterior line is geminate, the inner portion crenulate or lunate, the outer even. The ordinary spots may be yellow, white or concolorous, within the limits of the same species, but there are no other white shadings. In the common Eastern species there is no one prominent feature, and the secondaries are reddish or smoky. This, from its general

* Contributions towards a monograph of the Noctuidae of Boreal North America. Revision of the Hydroecia, Gn., by J. B. Smith. Transactions of the American Entomological Society, vol. xxvi, 1899-1900. 
locality, I have called atlantica, but as a matter of fact it extends to the Rocky Mountains in Colorado. This is the species which most resembles the European nictitans, but the sexual pieces of the male differ completely. Pacifica is so called from the fact that all the examples seen by me come from the Western Coast States. Interoceanica occurs so far only in the region about Winnipeg. These three species I would hardly have dared to separate from nictitans, had it not been for the differences in structure in the male genitalia, but these are so radical that specific identity is out of the question." Dr Smith's atlantica is identical with americana, Speyer (1875).

It is to be supposed that the figures of the "clasps" of these species given by Dr. Smith are more accurate than that of the supposed nictitans, but in any case, and even if allowance be made for great inaccuracies, it is evident that not one of these three species is identical with any of our four British representatives of the group.

I may here, perhaps, without presumption, utter a word of warning to students of Dr. Smith's works upon the genitalia. I have not come across his "definitions of terms," if such exist, but he appears to have transposed the terms "harpe" and "clasper," as used by previous writers, and it were well that his example should not be followed, as it causes confusion in an already confused field.

In 1902 ("Entom. Record," vol. xiv, pp. 116-117), Tutt gives a list of "Species and Forms of Lepidoptera, so far only recorded from the British Isles." Here he says of paludis, "a quite distinct species, but closely allied to H. nictitans," but he does not mention lucens, that insect being recognised on the Continent. My opportunity of investigation of Continental lepidoptera is strictly limited, but it is perhaps suggestive that of forty-four European and Asiatic Hydroecias belonging to this group now before me, there are several specimens which agree in appearance and in genitalia with lucens, but not one which I dare to name paludis.

It appears to have been at this point that I became interested in the study of the group. Nictitans and paludis being both common in my garden at Mucking, I desired to possess a series of lucens also. My friends responded according to their power, amongst them Mr. A. W. Bacot, who had been, with Mr. J. A. Simes, spending 
an autumn holiday in 1899 collecting upon and around the Crinan Canal. The specimens were placed in my cabinet and there rested for a time. Puzzled about the curious resemblance between the three series, I appealed to Mr. Tutt, who could give me his convictions, but no certainties. I appealed to Mr. F. N. Pierce, already widely known for his unceasing investigations, and found that he had only nictitans and had come to the conclusion that there was but one species after all. We vigorously attacked the problem from this new standpoint, and, using Mr. Bacot's material, I was surprised to find that I had stumbled upon a development of genitalia entirely different to nictitans, paludis and lucens. My discovery was announced in the "Entomologist's Record," vol. xx, p. 146 (1908); the insects were exhibited before the City of London Entomological Society, March 17th and May 22nd, and before the South London Entomological Society on April 13th of the same year. After due consideration the new insect was named Hydroecia crinanensis (after the locality in which it was first detected) in the "Entom. Record," vol. xx, p. 184.

I give the following description of the specimen I have selected as type; previous descriptions having been only comparative with the other species of the group.

\$. Hydroecia crinanensis, Burrows. Larger than $H$. nictitans. F.-w. slightly pointed at the apex, bright red-brown, longitudinal and transverse lines very distinct, fringes concolorous. Orbicular stigma, lighter than the ground-colour. Reniform stigma orange, full, fairly straight edged inwardly, lower lobe projecting outwardly, interior dividing lines faint. H.-w. red-brown, darker towards the outer margin; fringes yellow, the yellow colour intruding in dots upon the darker margin.

Type specimen taken by Mr. A. W. Bacot at Crinan Canal, September 1899.

In the same magazine, vol. xxii (1910), p. 80, is published an article by myself, describing and naming nine distinct forms.

Later, in the last-mentioned magazine, vol. xxii, p. 54 (1910), Mr. Tutt reviewed the position and unreservedly accepted our conclusions. This acceptance he kindly emphasised by his address before this Society before referred to.

This appears to have been Mr. Tutt's last word upon TRANS. ENT. SOC. LOND. 1911.-PART IV. (JAN.) 3 C 
the subject, and I am left with our preparations and specimens, Mr. Pierce's photographs, and the drawings which were so skilfully executed under Mr. Tutt's eye by Mr. Gatter, who has kindly sent them on to me.

In dealing with our material, Mr. Pierce and I found ourselves faced at the outset by a great difficulty. The likeness of these four species to one another is so extreme that although long series have been exhibited privately to experts, and publicly to most of the London, and some of the Provincial societies, no one has yet been able to point out a single feature by which they can be visually separated with certainty.

In size the imago of nictitans is perhaps the smaller. Crinanensis is a little larger, paludis from a little to considerably larger, and lucens generally much larger.

The colour of the fore-wings is as confusing as is the size. Paludis is usually of a dull yellow-brown, and by colour alone can generally be separated from the others. I have no specimen of the other three species quite this colour, they being always tinged with red, but both nictitans and lucens occasionally come very near to it. I have all four species quite red, but when paludis is red it remains still quite a different insect from lucens in appearance. Crinanensis is commonly very dark, sometimes almost melanic, but I have nictitans (from Scotland) almost as dark, and also paludis from my own garden. There is a tendency to the formation of a central dark band on the fore-wings in the lighter specimens, less common in nictitans but common in the rest. In shape of fore-wings all four species agree, the pointed apex being perhaps less marked in nictitans and crinanensis. In wing markings, also, all are alike-I should perhaps say, more correctly, that there is no one mark belonging to one species which is not to be found upon the others of the group. The orbicular stigma, for instance, is more generally distinct in nictitans, it is rarely distinct in paludis, often distinct in lucens, and frequently so in crinanensis. The reniform stigma is always full (that is to say, possesses the inner circumference toward the base of the wing) in nictitans, in crinanensis it is often almost full, in lucens and paludis it is never full. But all four forms have frequently the reniform stigma suffused, smudged, or ill-defined, owing to the absence of the fine interior lines. The same resemblance also appears in the colour of the stigmata, which 
in all species may be white, orange, or concolorous. The inferior wings of the males are less dark than those of the females, and there is sometimes in all species a thin light band parallel to the hind margin.* When, however, we came to consider the localities from which our specimens came, we appeared to be on firmer ground, although this also may be more or less deceptive, as the species may, and probably do overlap, as do nictitans and paludis in my garden. It appears, however, that nictitans is by far the most generally distributed. I have myself taken it in most localities in which I have collected during its season of flight, and I have received it from all parts of England, Scotland, Ireland and Wales. It appears also to be common on the Continent, and Asia.

Although the discrimination of the three species from nictitans is so difficult (apart from the appendages) that one cannot frame a description that will certainly enable any one else to distinguish them, and many find it difficult to believe that they really are distinct, it may be noted that Tutt distinguished the three British species with which he was acquainted long before the genitalia were examined, and would doubtless have distinguished the fourth (crinanensis) had he had it before him at the same time. But the marvellous critical instinct which Tutt had in such matters is very rare. Dr. Smith also can apparently easily distinguish from each other the three American species he describes, but without the assistance given by the appendages would have hesitated to regard their differences as of specific value.

Paludis is essentially a salt marsh and riverside species in the south of England. I cannot speak positively, but I believe it to be confined to the south, the specimens mentioned in Mr. Acton's paper, referred to above, being probably not this species at all. I have not, so far as I have been able to judge, received it from any locality out of England.

Lucens is essentially a "moss" species, and I should expect it to be confined to the north of England, Ireland, and perhaps Wales, and to Scotland, in its chosen haunts. It appears also to occur in Europe and Asia, if my more or less hasty examination of my material is to be trusted.

Crinanensis is a stream-side insect. Wherever it has

* The number of specimens here described is $H$. nictitans 40 $H$. paludis $33, H$. lucens $27, H$. crinanensis 46 , being my own series 
been taken, so far as I have been able to learn, its haunts are by running water irrespective of elevation, or of the neighbourhood of the sea.

Mr. J. G. Le Marchant, who found it in plenty near Aberfeldy, N.B., writes me thus: "There is a strip of marshy, boggy ground some two or three hundred yards wide, along the side of the river, and some three or four miles long. It is covered with coarse grasses, rushes, and a good many flowers, notably "scabious." There are also knapweed, hawkweed, and other flowers. It is along this strip that I have taken all the insects I send to you; there do not seem to be any on the slopes of the hills even close by. On the "Knowie," surrounded by rushes, they are very numerous when the sun is shining, sitting always on the scabious blossoms, sometimes three or four on a plant."

Mr. Buxton* at Liddelbank, N.B., and Mr. Sweetıng on Loch Foyle, also noticed the predilection of this insect for the scabious, which may indeed prove to be its food plant.

With crinanensis I have received a few nictitans and lucens, but I believe where it occurs this insect is found almost always alone.

The localities which I have recorded for this species are Inveran (Sutherlandshire), Maddison collection; Bellanoch, Crinan Caral, Messrs. Bacot and Simes; Aberfeldy, Le Marchant; Liddelbank, Messrs. Buxton; near Loch Foyle, H. R. Sweeting; near Enniskillen, in Co. Monaghan, and Bolton, Lancs., J. E. R. Allen.

All these insects appear in Britain at the end of August and beginning of September.

$\mathrm{Mr}$. Pierce and I had perforce, in the first instance, to differentiate our insects by locality. No difficulty arose as to finding the proper females of the species affecting my garden. Having separated the males of lucens from nictitans, we recognised the female of this insect by her difference from the other insect. Proceeding, we found the female of crinanensis by her difference from that of lucens and nictitans. We may, I feel, claim that our conclusions are fairly likely to be correct, though we admit that further examination, while it cannot well lessen the number of the species now under consideration, may possibly increase it.

* Mr. Buxton writes me that it was more often on thistle blossom. 
We turned next to the genitalia. As will be readily seen by the plates which accompany this paper, these organs in the four species-and in H. americana, Spr. (atlantica, Smith), the common North American species belonging to the same group-are closely related in general configuration, although the details are different. It is these differences that 1 would now point out.

First considering the males.

Taking our commonest species, $H$. nictitans, we find that the claspers (valves) are tipped with a more or less rounded head (cucullus). There are no external free angles; there are spines along the outer margin for about half its length (corona), and a bunch of spines upon the rounded, not pointed, anal angle. The "harpe" is bootshaped, the stout inner and outer branches being of equal length. The clavus is claw-shaped, curved towards the centre, and is clothed with hair. The "vesica" is armed with a bunch of long thin "cornuti." These vary in number between about four and eight; and also in length, but I have never observed any of these in this, or the other species, within the "bursa copulatrix" of the female.

In $H$. paludis there is a marked difference in the form of the "cucullus," which is larger, and distinctly angulated. The "corona" extends nearly three-quarters of the distance along the margin, the anal angle is obtusely pointed, and bears a large bunch of spines. The "harpe" is boot-shaped, but has a long toe and a short heel. The "clavus" is long and pointed at the end. The "cornuti" are short and stout, being some nine to twelve in number.

$H$. lucens has the "cucullus" much narrower than the last species. It is angulated-the "corona" extends further along the margin of the "cucullus," which is sharply pointed on the anal angle, and bears a proportionately smaller bunch of spines than does paludis. The "harpe" is boot-shaped, the toe long, much like the last species, but the heel is longer and strongly curved outwardly. The "clavus" is slightly shorter than in paludis, and often blunter at the tip, almost obtuse. The "cornuti" are long and fine, and from ten to twelve in number.

The genitalia of these three species are of similar type, but the remaining species which I have examined depart markedly from them.

$H$. crinanensis has the "cucullus" very much narrower than either lucens or paludis, being nearly twice as long as 
broad. It bears the "corona" only on the upper fourth of the margin, and is almost covered by spines. The "harpe" is without the boot-shaped termination, and is attached loosely to the stem of the "clasper." Beside the "harpe" is a thin semicircular plate of hard chitin serrated on its outer edge. This flap is attached loosely to the thin chitin of the inner surface of the valve, and appears to move readily backwards and forwards. The clavus is stout and incurved, very like that of $H$. nictitans, but is accompanied by a quadrate chitinous plate deeply serrated on its inner edge. The "cornuti," about twelve in number, are long and thick.

Thus far our British species. I am adding two exotic forms on account of their interest.

In $H$. americana (atlantica) we find the link between the last-named species and the other members of the group. The "valve" is nearly equal in width throughout its length, the "cucullus" being scarcely wider than the rest of the valve. The "corona" extends along three parts of the margin, and the "cucullus" is very heavily spined along the inner margin. The "harpe" is less bifurcate than in $H$. paludis, the "heel" being scarcely developed. The "clavus" is short and stout, claw-shaped, with a naked point, and is accompanied by a quadrate chitinous plate, toothed on its inner edge, and very like the similar appendage in $H$. crinanensis. The "cornuti" are of medium size, even in length, and about fourteen in number.

Quite recently I have found amongst a number of foreign Hydroecias given to me some time ago by Dr. Chapman a male labelled as from Turkestan, which we had catalogued after a preliminary examination as being $H$. crinanensis. More careful examination has proved that it does not belong to this species, but to another, of which, so far as I know, the genitalia have not been examined. This is again practically indistinguishable from the other species of the nictitans group. Its peculiarity is that the "valves" narrow off to the "cucullus," which is exceedingly narrow with parallel sides. The "harpe" without a foot, is just free from the surface of the "valve," more so than in $H$. crinanensis. The chitinous flap also found in $H$. crinanensis is very narrow. The "clavus" is claw-shaped, strong and thick, and is not accompanied by a chitinous plate as in the case of 
$H$. crinanensis and $H$. americana. The "cornuti" are very short, even in length, and about twenty-four in number.

It is, of course, quite possible, though extremely unlikely, that this insect may have been differentiated from the other Hydroecias, and have received a name. I would therefore suggest, conditionally, the name of $H$. asiatica, after the continent in which the label asserts it was captured, and append a description.

Hydroecia asiatica, $\delta$. Of the size of $H$. nictitans. F.-w. reddish-brown, orbicular and reniform stigmata somewhat paler, the former indistinct; the latter nearly full, being defective in the centre towards the base of the wing, the two lobes exteriorly uniform, the interior lines suffused. H.-w. lighter basally. From a single male labelled Syrt Naryn, Ost Turkestan. H. Rolle, Berlin, S.-W. N.

A further point of interest in this group of insects is the heavy pair of pencils of hairs upon the early abdominal segments, and the pockets in which they are contained. These are very evident, except in $H$. nictitans, in which species, if they occur, it is only in a much reduced and delicate form.

The females of the group provide fewer points for particular description. The main details upon which they can be differentiated are few, and as they present considerable discrepancies, I must acknowledge that I offer these notes with much diffidence as regards paludis and lucens. I depend upon the form of the genital plate and the lodix (i.e. the posterior edge of the seventh sternite).

In $H$. nictitans the genital plate is wide and shallow, the central excavation commencing from near the extremities, and presenting a wide right-angular cut. The lateral creases are near the upper (posterior) extremities. The "lodix" has a central narrow excavation.

In $H$. paludis the genital plate is wide and deep. The central excavation is shallow and rounded. The lateral creases are below the widest part of the plate. The lodix has a central deep, narrowly triangular, excavation with a rounded end.

In $H$. lucens the genital plate is wide and deep, slightly narrower, more substantial, and perhaps deeper than in $H$. paludis. The central excavation is shallow and rounded. The lateral creases are below the widest part of the plate. The lodix has a central deep triangular 
excavation. The genitalia of the females of $H$. paludis and $H$.lucens are extremely difficult to separate. There appears to be no absolutely certain difference except that the genital plate is perhaps more substantial in $H$. lucens than in $H$. paludis, and has also in $H$. lucens a tendency to fold in the centre, doubling over and presenting the appearance of a dark central line, which effect I ascribe to the plate being more full than in $H$. paludis.

In $H$. crinanensis the genital plate is wide and deep. The central excavation is extremely narrow and very deep, extending more than half-way through the plate. The lateral creases are above the widest part of the plate. The lodix has only the smallest possible central triangular excavation.

In $H$. americana the genital plate is wide and deep, the central excavation being $\mathbf{V}$-shaped. The lateral creases, diverging from about the centre of the side of the plate, extend obliquely in a straight line until they are lost in the posterior margin of the ninth segment. The excavation in the centre of the lodix appears as a wide sweeping curve.

(The specimen from which this description is taken is reasonably assumed to be $H$. atlantica.)

The number of specimens examined for these details of genitalia formation is as follows :-

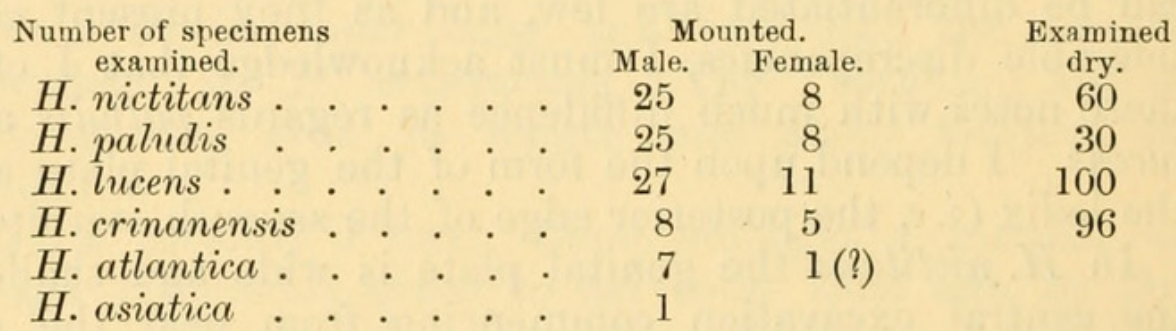

These differences in the appendages cannot be referred to geographical variation as, apart from their being too considerable, our four British species, though each having a special area of distribution (except nictitans, which is very widespread), have unquestionably no impediments to freely crossing with each other. But there are no indications that such ever takes place, there being no specimen at all intermediate discovered amongst all the examples examined.

In Acronicta psi and tridens we have a very similar case, affecting two species; the group before us presents eight. $P s i$ and tridens have very different larvae. In the species before us we have had practically nothing done in the way 


\section{$2 \mathrm{BHL}$ Biodiversity Heritage Library}

Burrows, C. R. N. 1912. "XXXIII. On the nictitans group of the Genus Hydroecia, Gn." Transactions of the Entomological Society of London 59, 738-749. https://doi.org/10.1111/j.1365-2311.1912.tb02206.x.

View This Item Online: https://www.biodiversitylibrary.org/item/51196

DOI: https://doi.org/10.1111/j.1365-2311.1912.tb02206.x

Permalink: https://www.biodiversitylibrary.org/partpdf/12086

\section{Holding Institution}

Smithsonian Libraries

\section{Sponsored by}

Smithsonian

\section{Copyright \& Reuse}

Copyright Status: Public domain. The BHL considers that this work is no longer under copyright protection.

This document was created from content at the Biodiversity Heritage Library, the world's largest open access digital library for biodiversity literature and archives. Visit BHL at https://www.biodiversitylibrary.org. 